Grant: DE-FG03-84ER45085

Robert Sinclair

Stanford University

\title{
APPLICATION OF QUATERNARY PHASE DIAGRAMS TO COMPOUND SEMICONDUCTOR PROCESSING
}

Isobaric, isothermal phase diagrams are a molar representation of condensed phases in equilibrium with each other at a fixed temperanre, pressure, and composition. Since three or four elements are usually involved at a fabricated interface in a semiconductor device, knowledge of the appropriate temary or quatemary phase diagram is imporant for optimizing the processing parameters and designing long term stablility of devices. While the use of phase diagrams is well-established in the fields of metallurgy, ceramics and mineralogy, only recently have phase diagrams been employed to provide a framework for understanding thin film reactions on a substrate, encountered in semiconductor processing. Even though there are many examples of applicasions of ternary phase diagrams in the semiconductor literanure (for instance, metallization of $\mathrm{GaAs}^{l}$, the use of refractory metal silicides for metallization layers in VLSI devices ${ }^{2,3}$ and oxidacion of III.V compoundsa), the same is not toue for quatemary phase diagrams. To date, the only application is oxidation of mercury cadmium tellurides. This lack of examples is not waranted, as four elements are often involved at a crivical interface in compound semiconductor processing and devices. This paper repors on the progress made to remedy this situation by considering the application of quaternary phase diagrams to understanding and predicting the behavior of II-VI thin film interfaces in photovoltaic devices under annealing conditions. Examples, listed in Table I, include semiconductor/insulator/semiconductor (SIS) layered stuctures, II-VI/I-VI and III.V/II-VI epitaxial' heterojunctions and oxidation of ternary compounds. Moreover; for the first time, solid solubility is taken into account for quatemary phase diagrams of semiconductor systems.

Inputing the tree energies of formation at a particular temperature and pressure for all the phases in the quatemary system into a computer program, a systematic and staightforward method to calculate the quatemary phase diagram has been developed. The technique extends the thermodynamic principles and properties of the isobaric, isothermal ternary phase diagram, which have their basis in the Gibbs phase rule ${ }^{3}$, one-dimension higher. Since sulphides, selenides, and tellurides are well-characterized systems thermochemically ${ }^{6}$, all 21 quatemary phase diagrams for the systems in Table I have been calculated, including the presence of solid solubility in many of the systems (Table I). Only in the most complicated case of quatemary solid solutions has solid solubility not 


\section{DISCLAIMER}

This report was prepared as an account of work sponsored by an agency of the United States Government. Neither the United States Government nor any agency thereof, nor any of their employees, make any warranty, express or implied, or assumes any legal liability or responsibility for the accuracy, completeness, or usefulness of any information, apparatus, product, or process disclosed, or represents that its use would not infringe privately owned rights. Reference herein to any specific commercial product, process, or service by trade name, trademark, manufacturer, or otherwise does not necessarily constitute or imply its endorsement, recommendation, or favoring by the United States Government or any agency thereof. The views and opinions of authors expressed herein do not necessarily state or reflect those of the United States Government or any agency thereof. 


\section{DISCLAIMER}

Portions of this document may be illegible in electronic image products. Images are produced from the best available original document. 
been included in the phase diagram calculations yet, but will be by the end of December 1988 when this research project is finished. In the next two sections, the Ga-As-II-VI and $\mathrm{Cd}-\mathrm{Te}-\mathrm{Zn}-\mathrm{O}$ phase diagrams are reviewed as examples of quaternary phase diagrams without and with solid solubility.

\section{The Ga-As-II-VI Phase Diagram}

The equilibrium molar representation for a ternary system, the two-dimensional Gibbs equilateral triangle, becomes a three-dimensional regular tetrahedron for a quaternary system. The pure elements occupy the corners, the six binary systems the edges, and the four temary systems the faces of the tetrahedron. Similar to temary phase diagrams, quaternary diagrams consist of tie-lines connecting pairs of mutuaily stable phases, but now they pass through the tetrahedron when all four elements are involved, as well as lie on the surfaces when only three elements are needed. Tie-triangle planes, i.e. three-phase stability domains which have an irregular triangular shape bounded by tie-lines along the edges and the phases in equilibrium with each other at the comers, are formed in the interior of the tetrahedron (hence they are also given the name pseudoternary planes) and also on the faces of the tetrahedron corresponding to the temary case. Analogous to the tietriangle region in a ternary diagram, the building block of the quatemary diagram is the tietetrahedron volume which corresponds to the maximum four-phase stability domain imposed by the Gibbs phase rule. The tie-tetrahedron volume is an irregular tetrahedron bounded by tie-triangle planes on the sides, tie-lines along the edges, and the four phases in equilibrium with each other at the comers. As a result of the Gibbs phase rule, the regular tetrahedron must be completely filled by non-overlapping tie-tetrahedron volumes. Finally, the computer program determines all tie-lines in the quaternary diagram in the following manner. Constructing all possible lines between two phases and triangular planes made from these lines, the program generates a mass-balanced equation at the intersection between a possible tie-line with another line and/or a triangular plane and calculates the Gibbs free energy of reaction to establish if the rie-line is stable or not. The direction of the reaction determines the stable configuration.

This straighforward and systematic approach to quatemary phase diagrams is illustrated for the Ga-As-II-VI system (now referred to as the Ga-As-M-X system) at room temperature $\left(298^{\circ} \mathrm{K}\right)$ and one amosphere pressure. Under these conditions, no solid solubility exists. Thus each phase, since it is pure and has negligible solid solubility with 
all other phases, is represented by a point. The first step, presented in Figure 1, is the construction of the four temary phase diagrams, which represent the exterior structure of the quaternary diagram, i.e. the intersection of the interior tie-triangles with the faces of the tetrahedron. All six II-VI semiconductor compounds considered here (ZnS, ZnSe, ZnTe, $\mathrm{CdS}, \mathrm{CdSe}$, and $\mathrm{CdTe}$ ) give rise to the same form of the ternary diagrams except in one case for $\mathrm{Se}$ in the Ga-As-X diagram. Some of these pseudobinary tie-lines have been confirmed experimentally and published in the literanure. In one case, the complete experimental diagram for the Ga-As- $\mathrm{Zn}$ system ${ }^{7}$ is in agreement with that in Figure 1. Other examples are the $\mathrm{ZnTe}_{\mathrm{As}} \mathrm{Te}_{3}$ tie-line ${ }^{8}$, the $\mathrm{ZnTe}-\mathrm{Zn}_{3} \mathrm{As}_{2}$ tie-line ${ }^{9}$, and the GaAs$\mathrm{GaTe}$ tie-line ${ }^{10}$. Also it has been shown that $\mathrm{GaAs}-\mathrm{Ga}_{2} \mathrm{Te}_{3}$ is not a true pseudobinary system, i.e. there is no tie-line between $\mathrm{GaAs}_{2}$ and $\mathrm{Ga}_{2} \mathrm{Te}_{3}{ }^{10.11}$.

Focussing on the Ga-As-Cd-Te system only, the exterior structure of the quatemary phase diagram is shown in Figure 2. This is a true perspective of the tetrahedron. Figure 3 illustrates one calculation the computer does in determining the interior structure of the tetrahedron. Looking at Figure 3a, the Cd-As-GaTe plane is shaded, demonstrating the possibility of two interior tie-lines, GaTe-Cd $3 \mathrm{As}_{2}$ and $\mathrm{GaTe}-\mathrm{CdAs} s_{2}$, which would then give rise to the tie-triangle, $\mathrm{Cd}_{3} \mathrm{As}_{2}-\mathrm{CdAs}_{2}-\mathrm{GaTe}$. However, this hypothetical tie-triangle needs to be checked against the alternate tie-line, GaAs-CdTe, according to the chemical reaction,

$$
4 \mathrm{GaAs}+4 \mathrm{CdTe}=\mathrm{Cd}_{3} \mathrm{As}_{2}+\mathrm{CdAs}_{2}+4 \mathrm{GaTe}
$$

The free energy of reaction is positive, thus making the GaAs-CdTe tie-line the stable configuration. This result has important implications for the production of opto-electronic devices, such as CdTe-HgTe multilayers or $\mathrm{Hg}_{\mathrm{x}} \mathrm{Cd}_{1-\mathrm{x}} \mathrm{Te}$ films on a $\mathrm{GaAs} / \mathrm{CdTe}$ substrate, since the original GaAs/CdTe interface will be stable as further processing is done to corsplete the device. The complete results for the Ga-As-Cd-Te phase diagram are depicted in Figure 4. The interior structure of the quatemary diagrams for all Ga-As-II-VI systems, summarized in Figure 5, shows all II.VI compounds in equilibrium with GaAs. Another significant outcome from these calculations is that all $\mathrm{MGa}_{2} \mathrm{X}_{4}$ compounds are stable on GaAs, thus making GaAs a suitable substrate to grow thin films of $\mathrm{MGa}_{2} \mathrm{X}_{4}$ compounds with their useful semiconducting and nonlinear optical properties.

Experimentally, the stability of CdTe, $\mathrm{ZnTe}$ and $\mathrm{CdS}$ on GaAs has been confirmed by carrying out $x$-ray diffraction of thin films annealed at $600^{\circ} \mathrm{C}$ for 100 hours. Also in situ annealing of the GaAs/CdTe heterojunction in a high-resolution electron microscope at a nominal temperature of $500^{\circ} \mathrm{C}$ for 40 minutes produced no evidence of a reaction. Crisp 
near-atomic-resolution images show that while there is significant dynamic motion in the CdTe thin film itself, the interface is stable. Presently, similar work is being performed to characterize the GaAs/ZnTe and GaAs/CdS heterojunctions. Phase diagrams have also been published, which demonstate the true pseudobinary behavior of the GaAs-CdSe and GaAsZnSe systems ${ }^{12.13}$.

\section{The $\mathrm{Zn}$-Cd-Te-O Phase Diagram}

The importance of ternary II-VI alloys for photovoltaic devices, such as tandem heterojunction solar cells, and opto-electronic devices, such as light emitring diodes, has spurred the development of alloy-growth techniques. This in turn has created a need for accurate thermochemical data and knowledge of liquid-solid phase equilibria in II-VI pseudobinary and temary systems. Various models have been used to estimate, both theoretically and empirically, the free energy of mixing, which is the thermodynamic quantity needed to build phase diagrams for systems with solid solubility. Results from studies on determining the thermodynamic mixing parameters in II-VI solid solutions are used in this research to construct temary and quaternary phase diagrams to predict solid state reactions. One important application is the passivation of temary alloys by oxidizing their surfaces. Oxidation of $\mathrm{Zn}_{\mathrm{x}} \mathrm{Cd}_{1-\mathrm{x}} \mathrm{Te}$ is discussed below as an example of calculating quatemary phase diagrams for systems with solid solubility.

When the $\mathrm{Zn}_{\mathrm{x}} \mathrm{Cd}_{1-\mathrm{x}}$ Te temary compound is modeled as a regular solid solution with mixing parameter $\mathrm{W}=1.34 \mathrm{kcal} / \mathrm{mole}$, the known $\mathrm{ZnTe}-\mathrm{CdT}$ e pseudobinary lens shape phase diagram is duplicated quite well ${ }^{14}$. Treating this. fontinuous solid solution as nine discrete compounds across the composition range, $x=0$ to $x=1$, and calculating the frée energy of formation for each discrete ternary phase using the above mixing parameter value in a regular solution model, one obtains the $\mathrm{Zn}$-Cd-Te room temperature ternary phase diagram in Figure 6. Along with the other temary phase diagrams in Figure 6, the exterior structure of the $\mathrm{Zn}$-Cd-Te-O quaternary diagram can be constructed as shown in Figure 7. Results from the computer analysis of the interior structure is presented in Figure 8. Confirmation of the phase diagram was obtained from $x$-ray diffraction of oxidized $\mathrm{Zn}_{3} \mathrm{Cd} .7 \mathrm{Te}$ single crystal substrates, which produced $\mathrm{ZnO}$ and $\mathrm{ZnTeO}{ }_{3}$ peaks.

\section{Summary of II-VI Quaternary Phase Diagrams}

Oxidation of the other II-VI temary alloys are summarized in Figures 9 to 11. There is no known published experimental data to test their predictions. The solid solurion tie- 
lines not shown here are bounded by the tie-lines berween the pure phases, similar to the $\mathrm{Zn}-\mathrm{Cd}-\mathrm{Te}-\mathrm{O}$ case. This results from the near ideality behavior in all cases.

The other oxygen containing systems, with no solid solubility however, are $\mathrm{Cd}-\mathrm{Te}$ S-O, $\mathrm{Zn}-\mathrm{Te}-\mathrm{S}-\mathrm{O}$ and S-Se-Te-O. The reader is referred to last year's progress report for results on the Cd-Te-S-O quatemary phase diagram, which is similar to the $\mathrm{Zn}-\mathrm{Te}-\mathrm{S}-\mathrm{O}$ phase diagram.The S-Se-Te-O phase diagram while calculated is not of technological interest and so not shown here.

Figure 12 shows the non-oxygen containing quatemary phase diagrams for II-VI systems with solid solubility. The left-hand column is for systems with temary solid solutions only. Again the solid solution tie-lines are not shown, but are bounded by the tielines between the pure phases forming the endpoints of the solid solution line compounds. Solid solubility for the quatemary solid solutions in the right-hand column has not been taken into account yet. Experimental results from $x$-ray diffracation of annealed $C d S$ plus $\mathrm{ZnTe}$ powders verify the reaction products $\mathrm{CdTe}$ and $\mathrm{ZnS}$ plus their temary solid solutions. Experiments are currently underway to study the corresponding thin film reaction between $\mathrm{ZnTe}$ and $\mathrm{CdS}$ using in siru high temperature annealing in an HREM equipped with a video recorder, thus allowing direct observations of the mechanisms by which this reaction occurs at the atomic level. Other researchers have also confirmed with $\mathrm{x}$-ray diffraction the reaction products $\mathrm{CdTe}, \mathrm{ZnS}$ and their temary solid solutions from annealed $\mathrm{CdS}$ and $\mathrm{ZnTe}$ powders ${ }^{15,16}$ as well as from the epitaxial thin film structure ${ }^{17}$. Quasi-binary behavior, i.e. a tie-line between the two phases, has also been demonstrated for $\mathrm{CdSe}_{\mathrm{ZnS}}{ }^{18}$ and $\mathrm{ZnSe}$ CdTe ${ }^{19}$. The former result is in agreement with the phase diagram prediction in this report while the latter one is not. However, the predicted $\mathrm{ZnTe-CdSe}$ ie-line is stable only by 0.6 $\mathrm{kcal} / \mathrm{mole}$, which is within experimental error and therefore not a reliable prediction.

This report has summarized the work done on phase equilibria in II-VI quaternary systems over the last year. In general, the phase diagram depicts the geometric relationship among thermodynamic variables for phases in equilibrium with each other under an established set of conditions. Each type of thermodynamic system has a particular set of intensive variables which, when plotted against each other, best elucidate the equilibrium conditions. Isobaric, isothermal phase diagrams are used to predict solid state reactions in ternary and quatemary systems. This research has illustrated that a rigorous and methodical technique using the computer to construct quaternary phase diagrams can be successfully applied to a wide range of II-VI semiconductor systems, even for systems with solid solubility. 
1 R.Beyers, K.B. Kim and R. Sinclair, J. Appl. Phys. 61, 2195 (1987).

2 R. Beyers, R. Sinclair and ME. Thomas, J. Vac. Sci. Technol. B2, 781 (1984).

${ }^{3}$ R. Beyers, J. Appl. Phys. 56, 147 (1984).

4 G.P. Schwartz, Thin Solid Films 103, 3 (1983).

5 D.R. Rhiger and R.E. Kvaas, J. Vac. Sci. Technol. Al, 1712 (1983).

${ }^{6}$ I. Barin, O. Knacke and O. Kubaschewski, Thermochemical Properties of Inorganic Substances, SpringerBerlin, 1977.

7W. Koster and W. Ulrich, Z. Metallk. 49, 361 (1958).

${ }^{8}$ I.D. Olekseyuk, M.I. Golovei, I.M. Swika and I.I. Yatskovich, Lzv. Akad. Nauk SSSR, Neorgan. Mat. 11, 2081 (1975).

${ }^{9}$ I.D. Olekseyuk, M.I. Golovei and N.A. Goryunova, Izv. Akad. Nauk SSSR, Neorgan. Mat. 1, 747 (1971).

${ }^{10}$ M.B. Panish, J. Electrochem. Soc. 114, 91 (1967).

11J.C. Woolley and B.A. Smith, Proc. Phys. Soc. (London) 72, 867 (1958).

12V.M. Glazov, L.M. Pavlova and L.I. Perederii, Lzv. Akad. Nauk SSSR, Neorgan. Mat. 12193 (1983).

${ }^{13}$ V.M. Lakeenkov, M.G. Mil'vidskii and O.V. Pelevin, Lzv. Akad. Nauk SSSR, Neorgan. Mat. 11, 1311 (1975).

${ }^{14}$ P. Letardi, N. Motta and A. Balzarotti, J. Phys. C: Solid State Phys. 20, 2853 (1987).

15V.N. Tomashik, G.S. Oleinik and I.B. Mizetskaya, Lzv. Akad. Nauk SSSR, Neorgan. Mat. 14,1838 (1978).

${ }^{16}$ A.G. Fischer and R.J. Paff, J. Phys. Chem. Solids 23, 1479 (1962).

${ }^{17}$ M. Aven and H.H. Woodbury, Contract AF19 (604) repor AFCRL 62.141, 27 (1962).

18Y.N. Tomashik, G.S. Oleinik, I.B. Mizetskaya and G.N. Novitskaya, Izv. Akad. Nauk SSSR, Neorgan. Mat. 17,17 (1979).

${ }^{19}$ G.S. Oleinik, VN. Tomashik, I.B. Mizetskaya, G.N. Novitskaya and V.P. Chalyi, Izv. Akad. Nauk SSSR, Neorgan. Mat - 13. 1976 (1977). 
TABLE I

QUATERNARY SYSTEMS OF INTEREST

QUATERNARY

SYSTEMS

1. $\mathrm{Zn}-\mathrm{Cd}-\mathrm{O}-\mathrm{S}$

2. $\mathrm{Zn}-\mathrm{Cd}-\mathrm{O}-\mathrm{Se}$

3. $\mathrm{Zn}-\mathrm{Cd}-\mathrm{O}-\mathrm{Te}$

4. Zn-Cd-S-Se

5. Zn-Cd-S-Te

6. Zn-Cd-Se-Te

7. $\mathrm{Zn} \cdot \mathrm{O}-\mathrm{S}-\mathrm{Se}$

8. $\mathrm{Zn}-\mathrm{O}-\mathrm{S}-\mathrm{Te}$

9. Zn-O-Se-Te

10. $\mathrm{Zn} \cdot \mathrm{S} \cdot \mathrm{Se}-\mathrm{Te}$

11. Cd-O-S-Se

12. Cd-O-S-Te

13. Cd-O-Se-Te

14. Cd-S-Se-Te

15. O-S-Se-Te

16 Ga-As-Zn-s

1i. Ga-As-Zn-Se

18. Ga-As-Zn-Te

19. Ga-As-Cd-S

20. Ga-As-Cd-Se

21. Ga-As-Cd-Te
APPLICATION

HETERORNCTIONS

SIS STRUCTURES

OXIDATION

ZnO/CdS; ZnS/CdO

ZnO/CdSe; CdO/ZnSe

ZnS/oxide/CdS

$\mathrm{ZnCdS}$

ZnSe/oxide/CdSe

ZnCdSe

ZnO/CdTe; CdORnTe

$\mathrm{ZnTe} / \mathrm{oxide} / \mathrm{CdTe}$

ZnCdTe

ZnSe/CdS; CdSe/ZnS

ZnS/CdTe; CdS/ZnTe

ZnSe/CdTe; CdSe/ZnTe

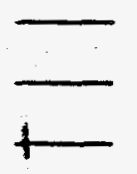

ZnS/oxide/ZnSe

ZnSSe

ZnS/oxide/ZnTe

ZnSe/oxide/ZnTe

ZnSeTe

CdS/oxide/CdSe

CdSSe

CdS/oxide/CdTe

CdSe/oxide/CaTe

CdSeTe

GaAs/Zns

GaAs/Znse

GaAs/ZnTe

GaAs/CdS

GaAs/CdSe

GaAs/CdTe

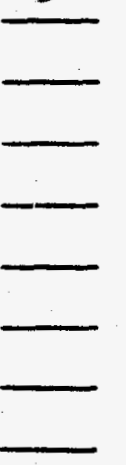


TABLE II

SOLID SOLUBILITY IN II-VI SEMICONDUCTOR BASED QUATERNARY SYSTEMS

QUATERNARY

SOLID SOLUTIONS -

SYSTEMS

TERNARY

QUATERNARY

1. $\mathrm{Zn}-\mathrm{O}-\mathrm{S}-\mathrm{Te}$

2. Cd-O-S-Te

3. O-S-Se-Te

4. Ga-As-Zn-S

5. Ga-As-Zn-Se

6. Ga-As-Zn-Te

7. Ga-As-Cd-S

8. Ga-As-Cd-Se

9. Ga-As-Cd-Te

10. $\mathrm{Zn} \cdot \mathrm{Cd} \cdot \mathrm{O}-\mathrm{S}$

$\mathrm{ZnCdS}$

11. Zn-Cd-O-Se

ZnCdSe

12. $\mathrm{Zn}-\mathrm{Cd}-\mathrm{O}-\mathrm{Te}$

$\mathrm{ZnCdTe}$

13. $\mathrm{Zn}-\mathrm{O}-\mathrm{S}-\mathrm{Se}$

ZnSSe

14. $\mathrm{Zn}-\mathrm{O}-\mathrm{Se}-\mathrm{Te}$

ZnSeTe

15. Cd-O-S-Se

16. Cd-O-Se-Te

CdSSe

CdSeTe

17. Zn-Cd-S-Te

ZnCdS, ZnCdTe

ZnSSe, ZnSeTe

Zn-S-Se-Te

CdSSe, CdSeTe

20. $\mathrm{Zn}-\mathrm{Cd} \cdot \mathrm{S}-\mathrm{Se}$

ZnCdS, ZnCdSe, ZnSSe, CaSSe

ZnCdSSe

21. $\mathrm{Zn}-\mathrm{Cd}-\mathrm{Se}-\mathrm{Te}$

ZnCdSe, ZnCdTe, ZnSeTe, CdSeTe

ZnCdSeTe 

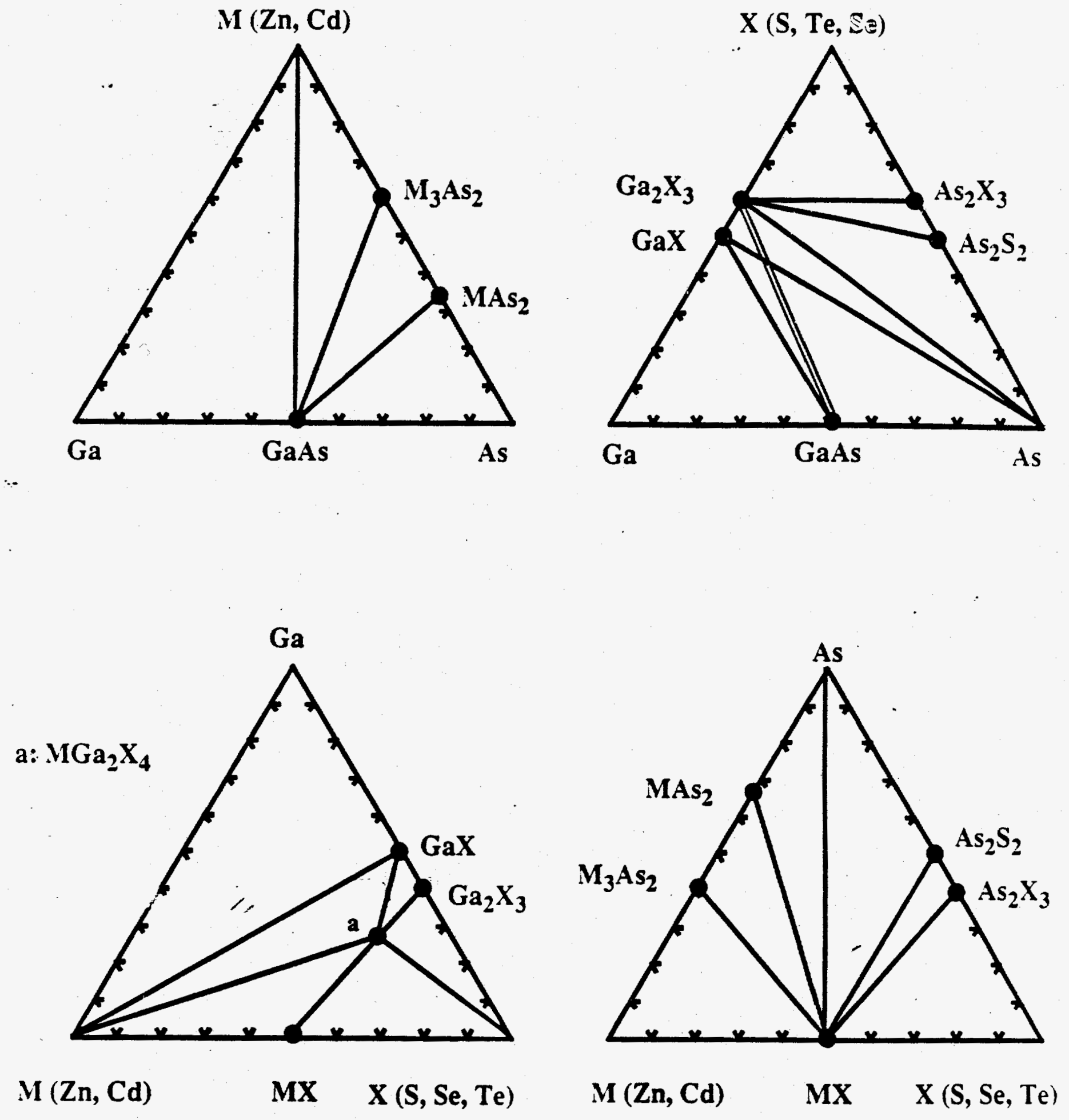

Figure 1. The four room temperature ternary phase diagrams for the Ga-As-II-VI systems. All solid black tie-lines exist for all cases except for the one intersected by the outlined tie-line for the Se case in the Ga-As-X diagram. Note that only for the sulphides, do the tie-lines emanating from $\mathrm{As}_{2} \mathrm{~S}_{2}$ exist. 


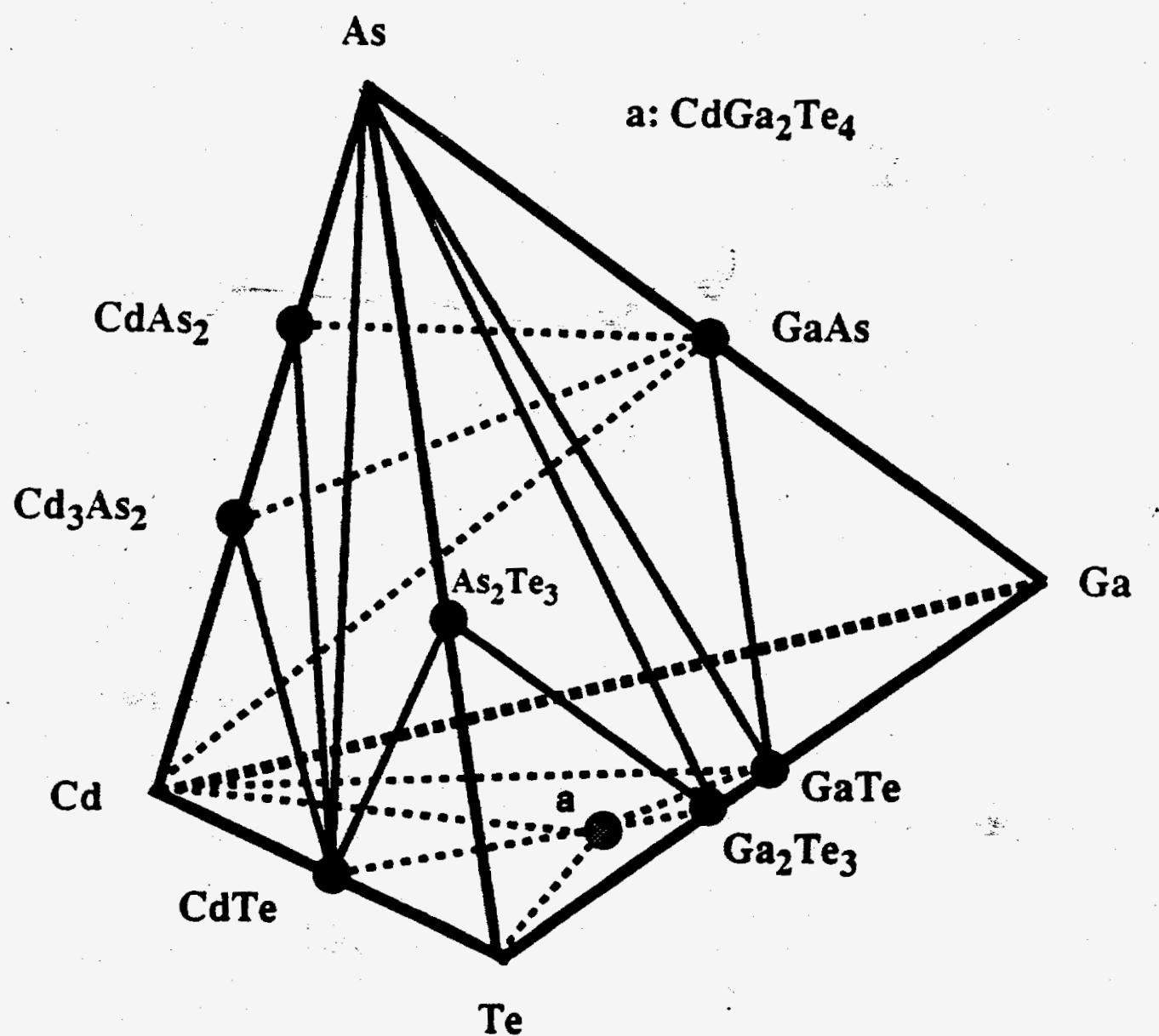

Figure 2. The exterior structure of the room temperature Ga-As-Cd-Te quatemary phase diagram. 
(a)

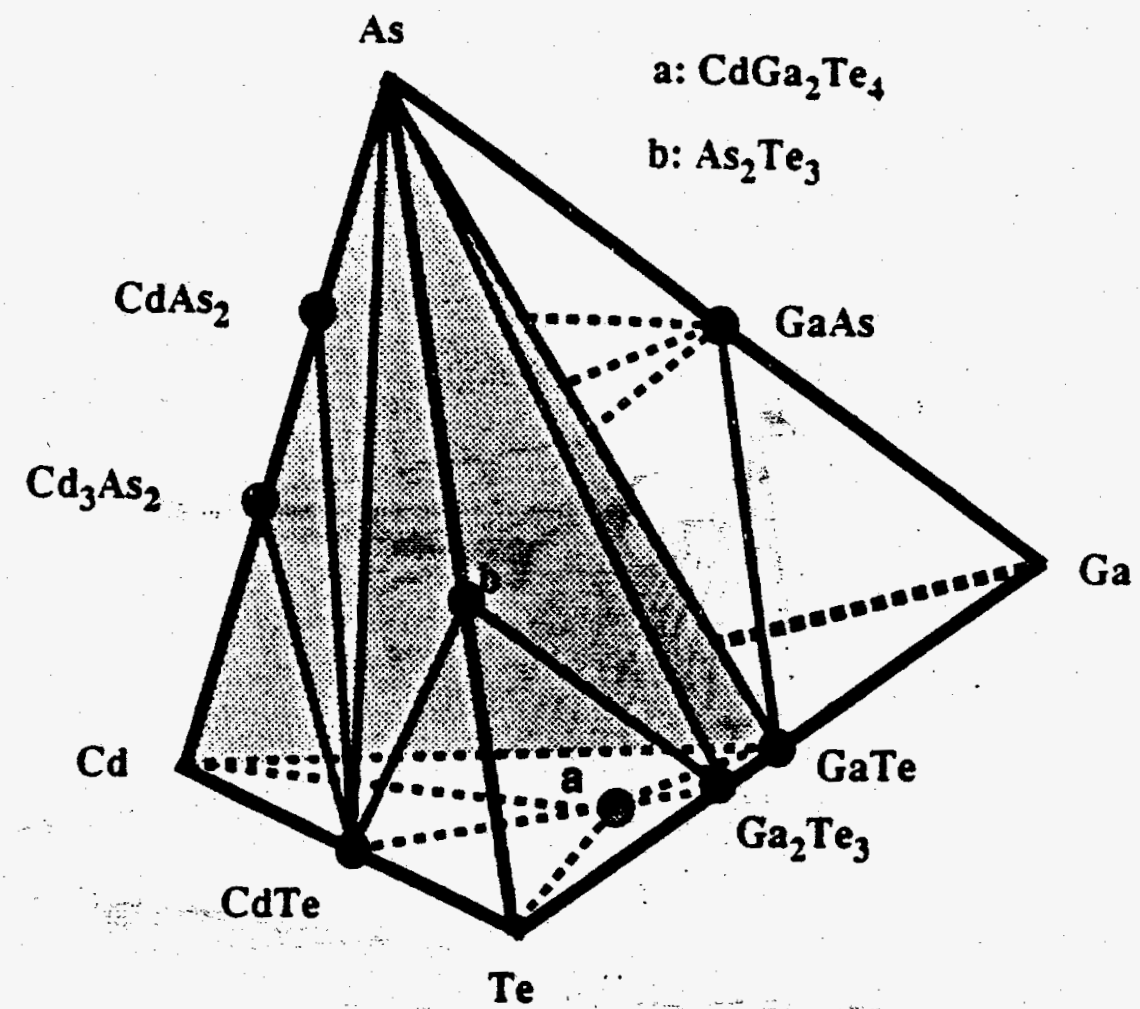

(b)

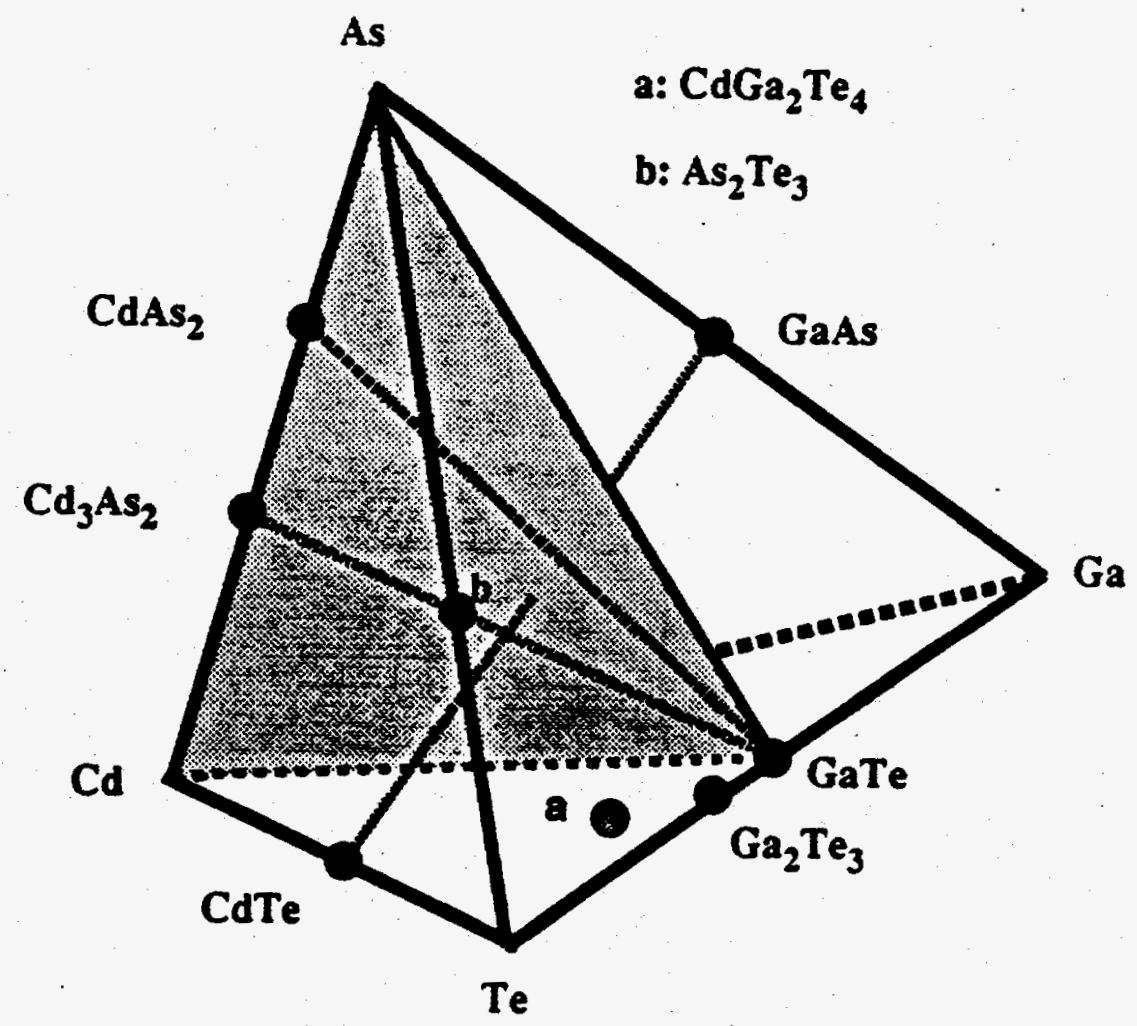

Figure 3. Construction of the interior region of the quatemary phase diagram requires comparing intersecting lines as in ternary phase diagrams as well as lines against tie-triangle planes. The Cd-As-GaTe plane is shaded (a) in order to illustrate the possible tie-triangle plane, $\mathrm{Cd}_{3} \mathrm{As}_{2}-\mathrm{CdAs}_{2}-\mathrm{GaTe}$, which needs to be checked against the GaAs-CdTe tie-line (b). The latter case is the equilibrium configuration. 


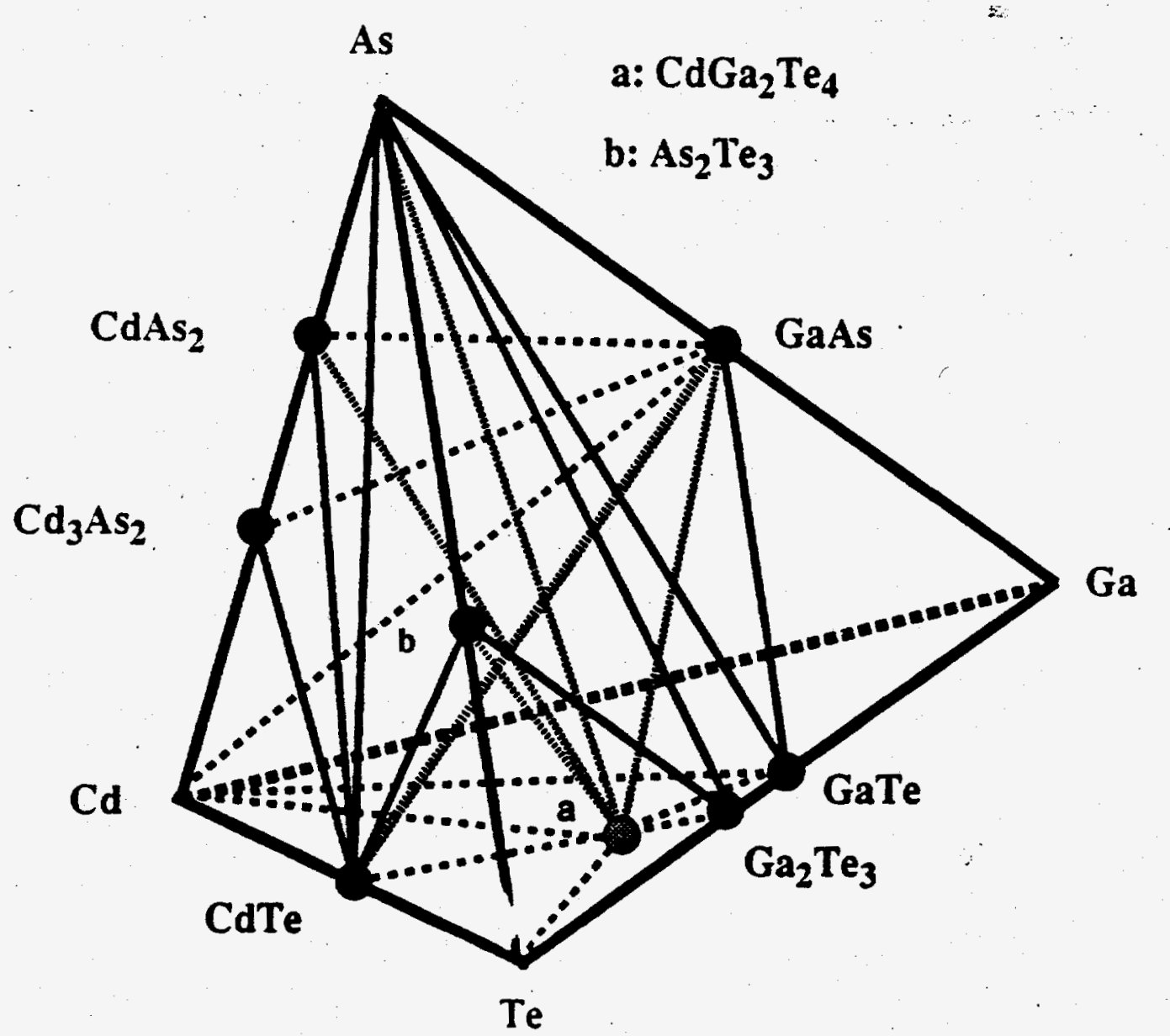

Figure 4. The complete room temperature Ga-As-Cd-Te phase diagram. 


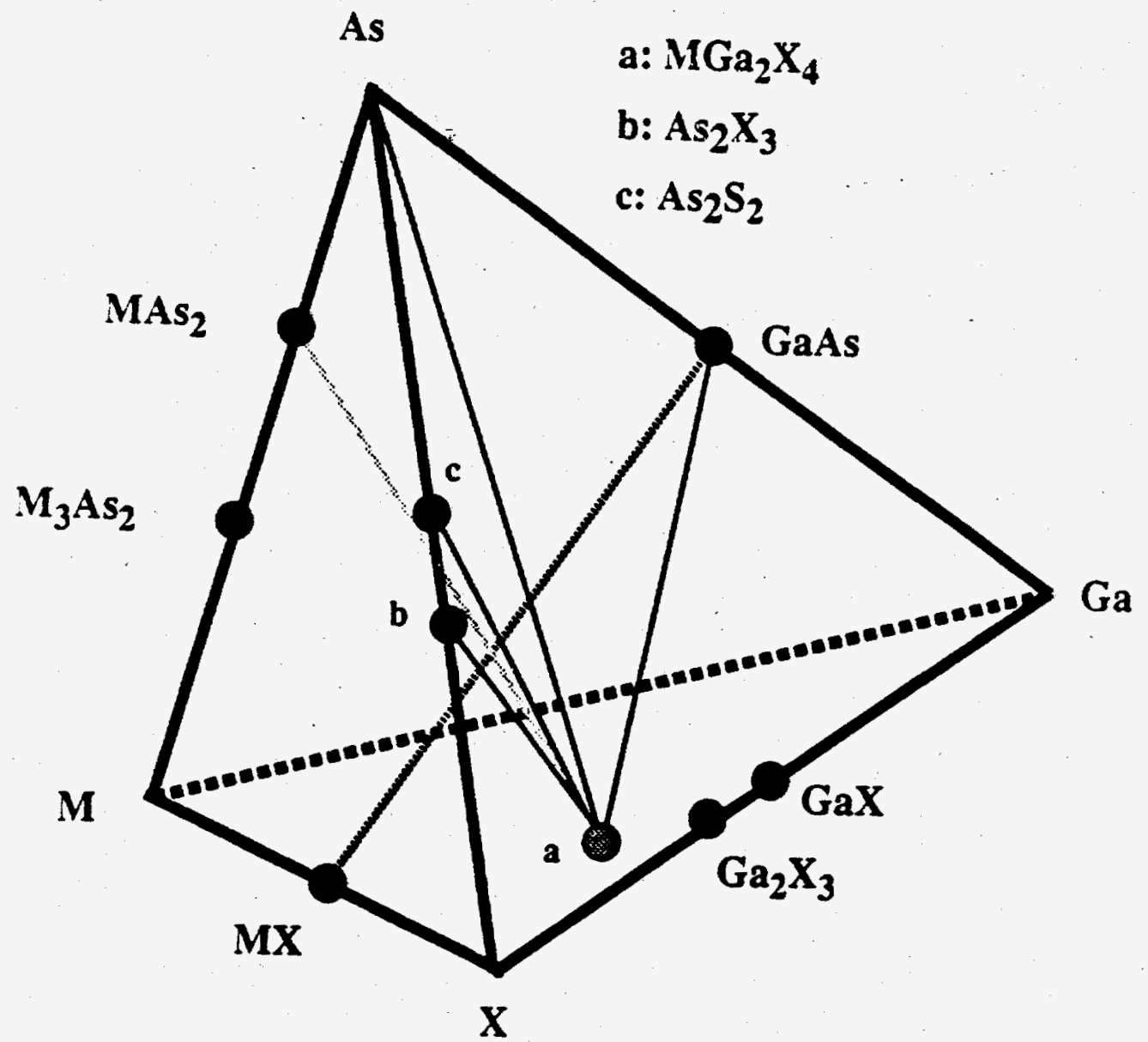

Figure 5. The room temperature interior tie-lines for the Ga-As-II-VI quaternary phase diagrams. The solid black tie-lines exist for all cases. The solid gray tie-line is true for all cases except for CdSe. 

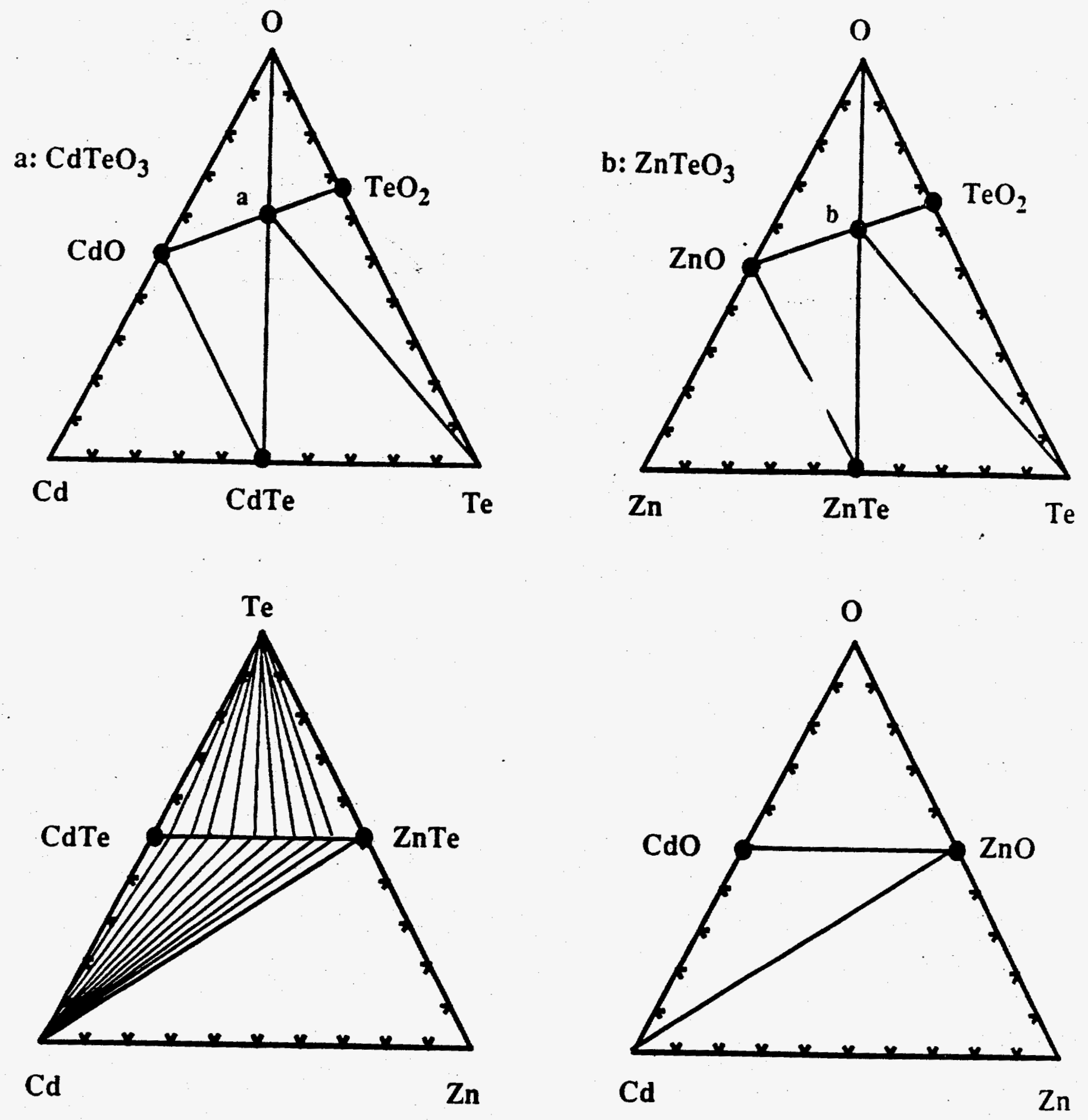

Figure 6. The four room temperature temary phase diagrams for the $\mathrm{Zn}-\mathrm{Cd}-\mathrm{Te}-\mathrm{O}$ system. The $\mathrm{Zn}_{\mathrm{x}} \mathrm{Cd}_{1-\mathrm{x}}$ Te ternary compound is treated as a reguiar solid solution. 


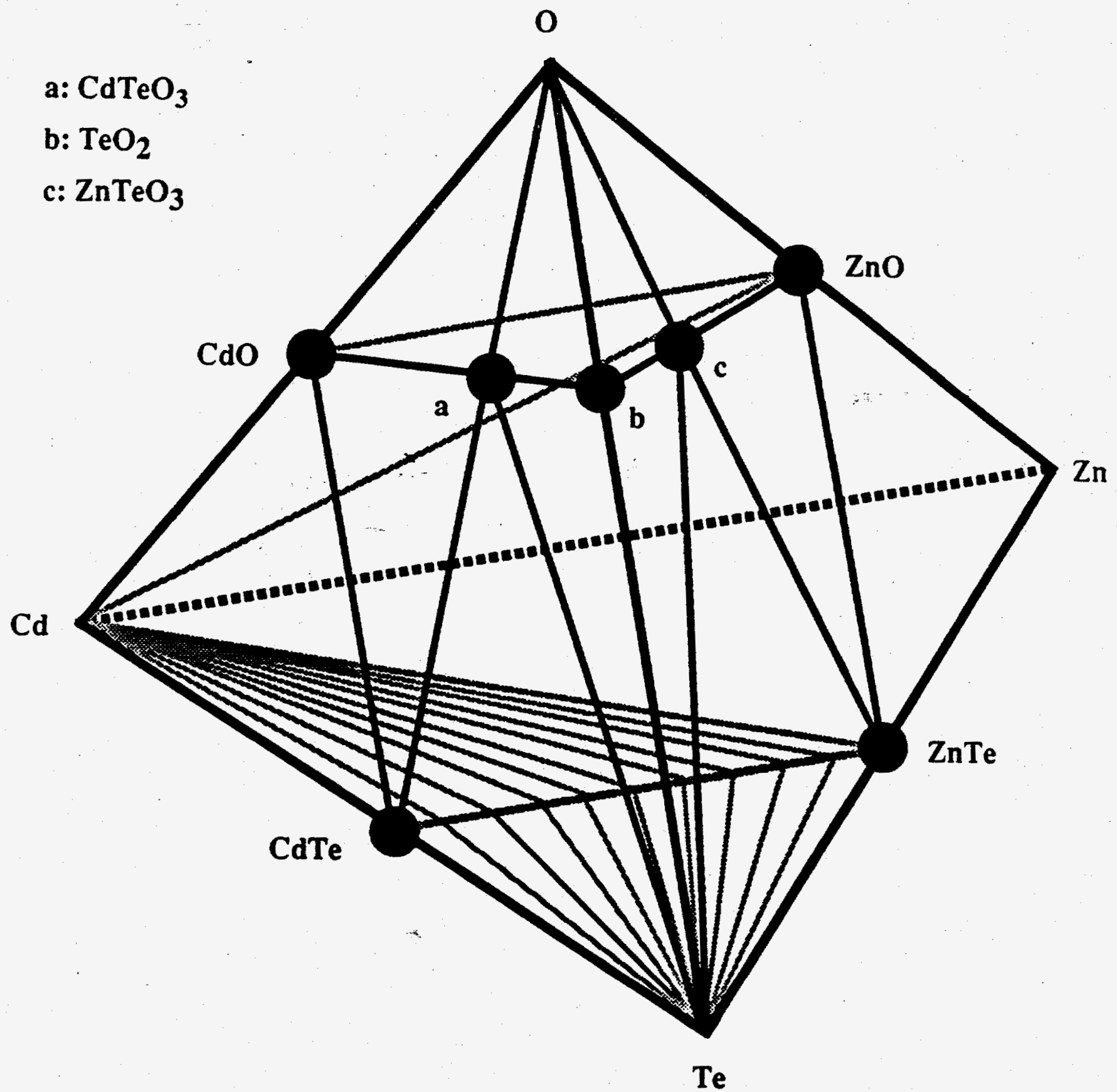

Figure 7. The exterior structure of the room temperature $\mathrm{Zn} \cdot \mathrm{Cd}-\mathrm{Te}-\mathrm{O}$ quatemary phase diagram. Tie-lines on the back and bottom faces are solid and shaded gray. 
(a)

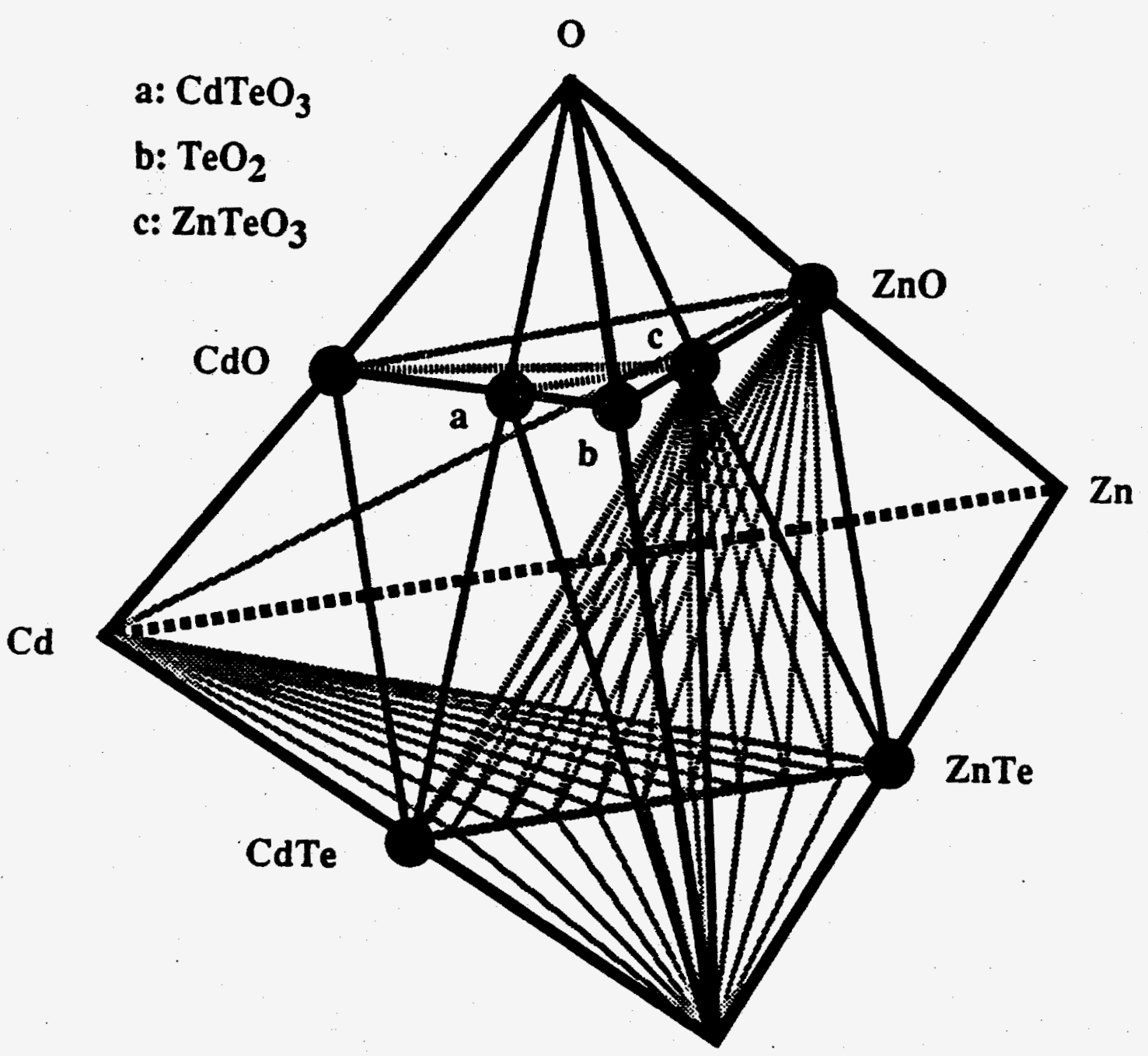

Te

(b)
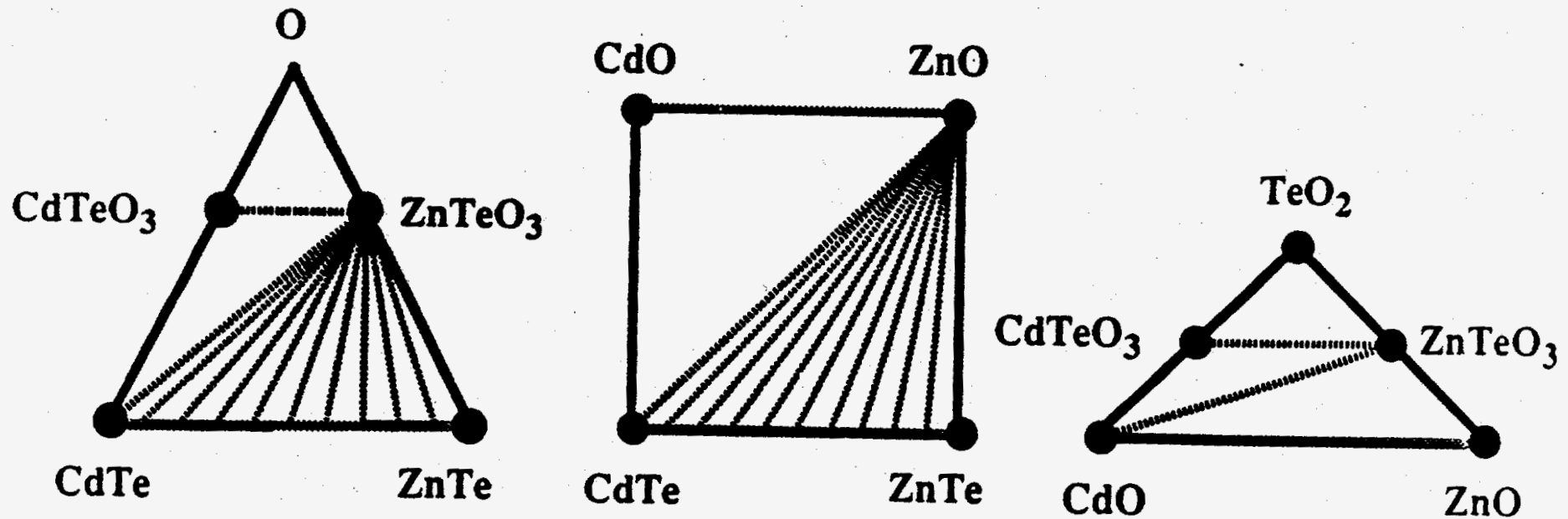

Figure 8. (a) The complete $\mathrm{Zn}-\mathrm{Cd}-\mathrm{Te}-\mathrm{O}$ room temperature quatemary diagram.

(b) The interior structure of the tetrahedron. 

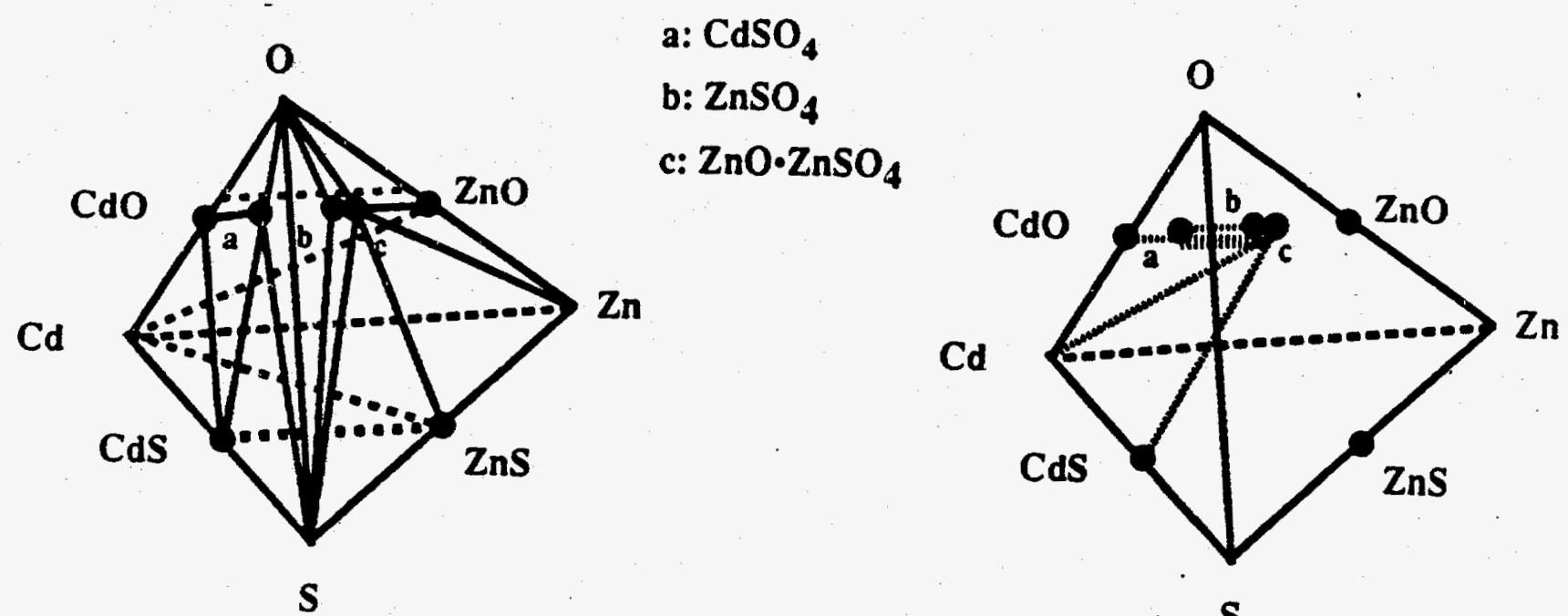

$\mathrm{S}$
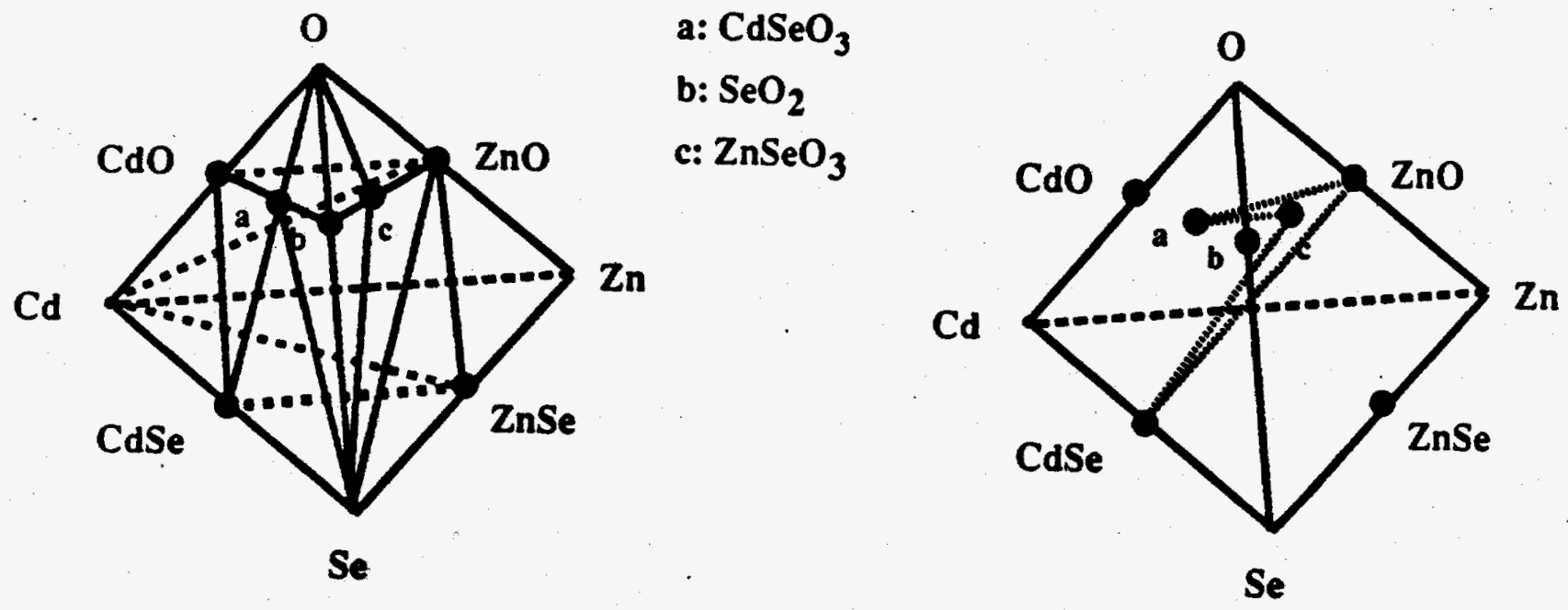

Figure 9. Quaternary phase diagrams for oxidation of cation temary solid solutions. 

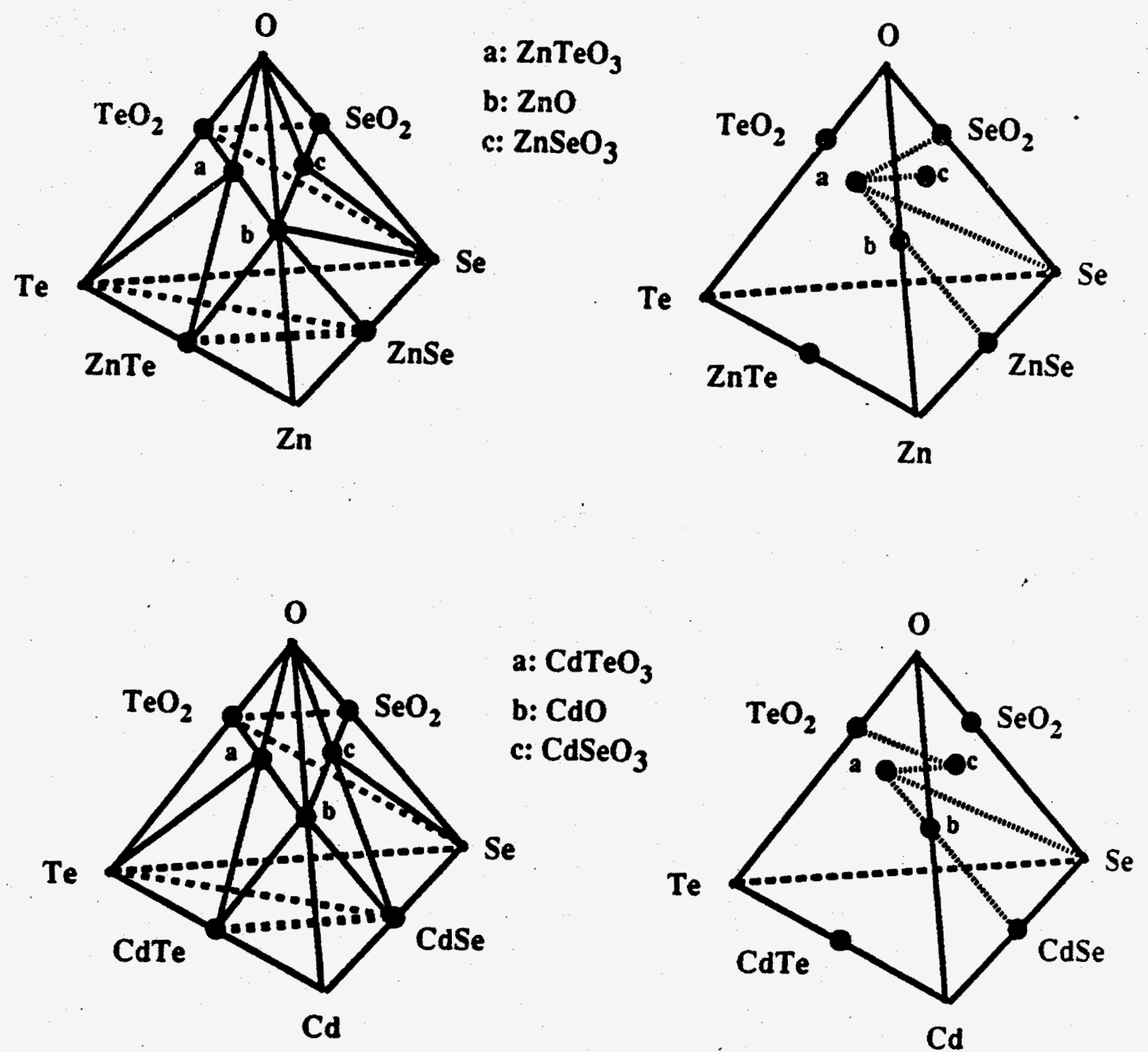

Figure 10. Quaternary phase diagrams for oxidation of anion ternary alloys based on $\mathrm{Te} / \mathrm{Se}$ substitution. 


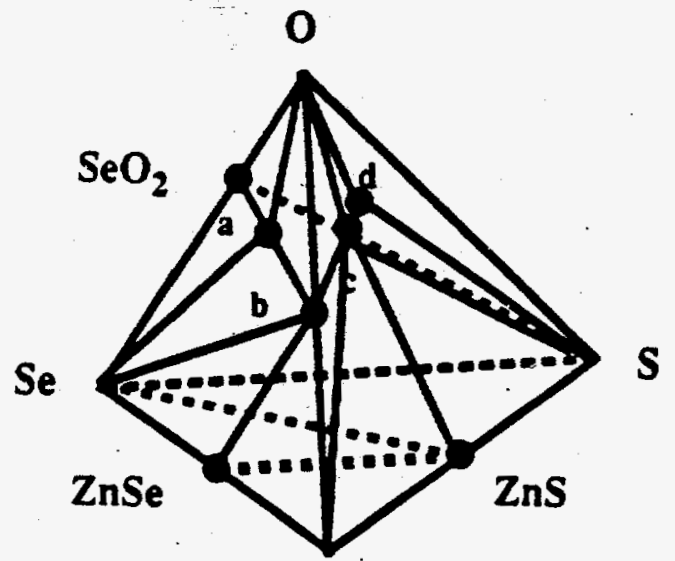

Zn a: $\mathrm{ZnSeO}_{3}$

b: $\mathrm{ZnO}$

c: $\mathrm{ZnO} \mathrm{ZnSO}_{4}$

d: $\mathrm{ZnSO}_{4}$

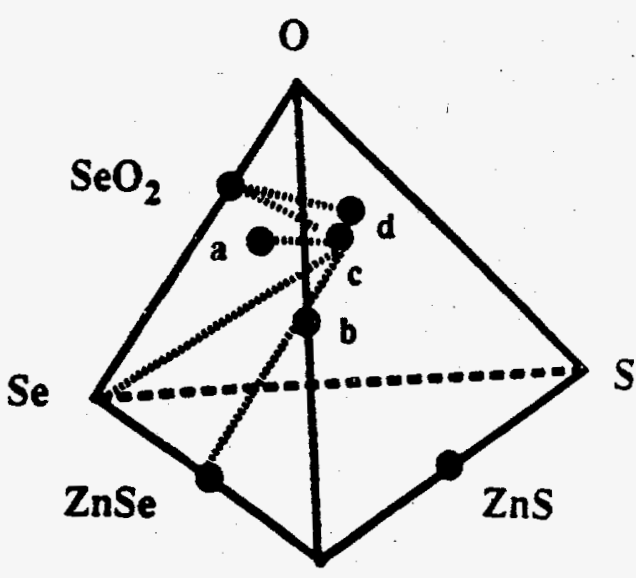

Zn

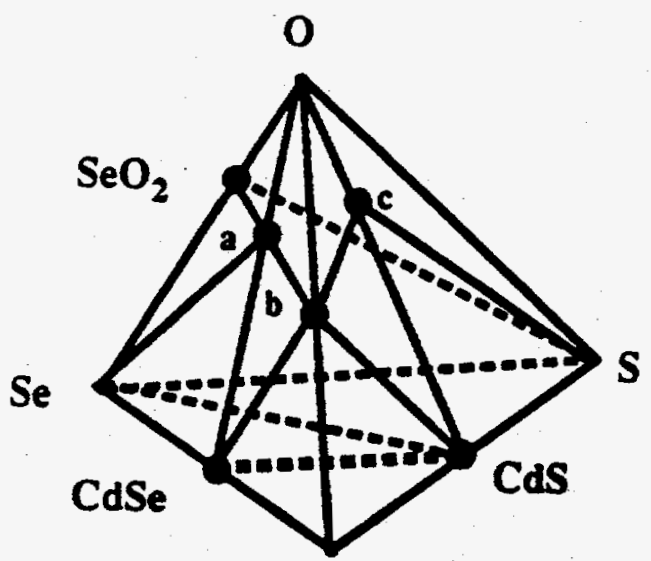

Cd
a: $\mathrm{CdSeO}_{3}$
b: $\mathrm{CdO}$
c: $\mathrm{CdSO}_{4}$

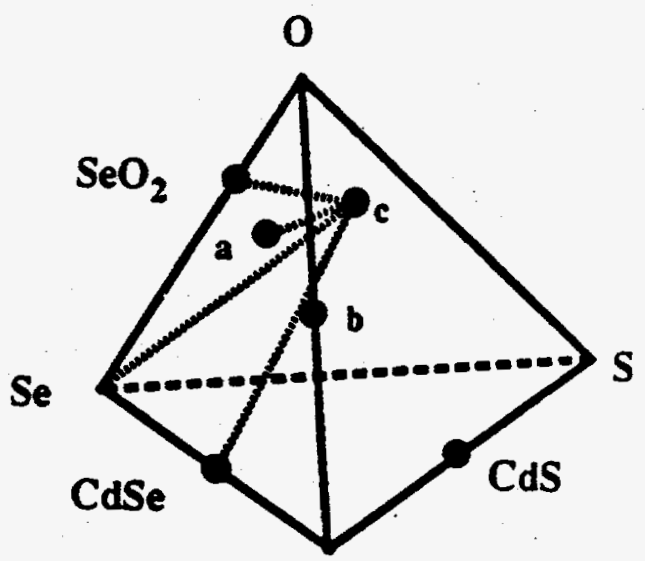

Cd

Figure 11. Quaternary phase diagrams for oxidation of anion ternary alloys based on S/Se substitution. 


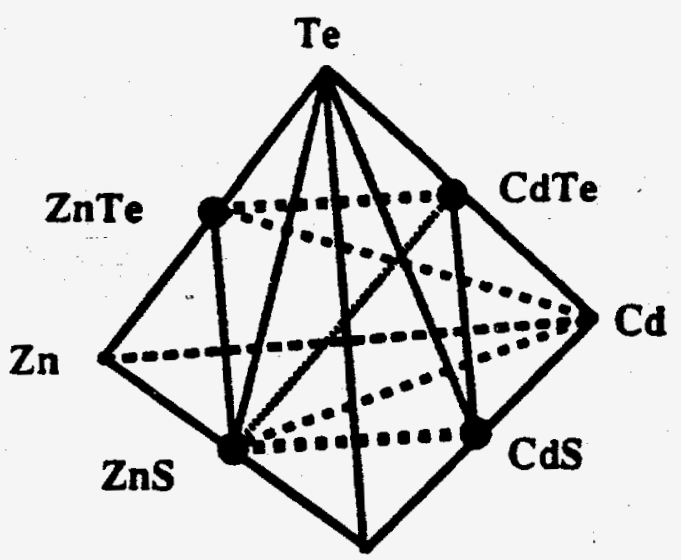

S

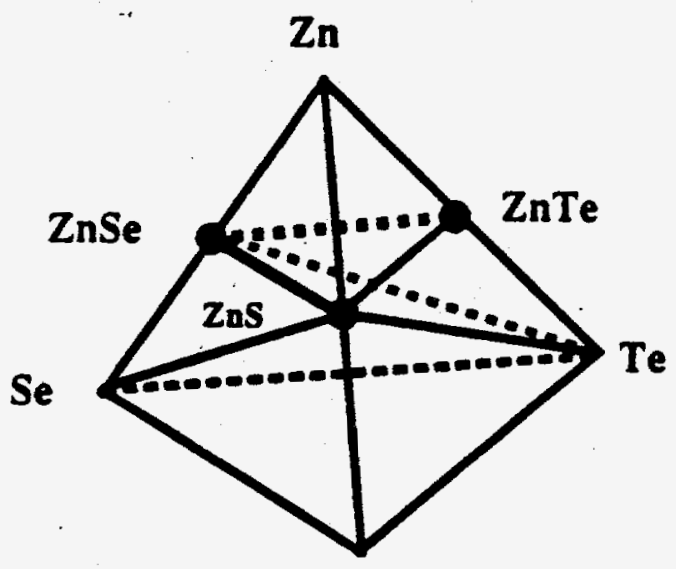

$\mathbf{S}$

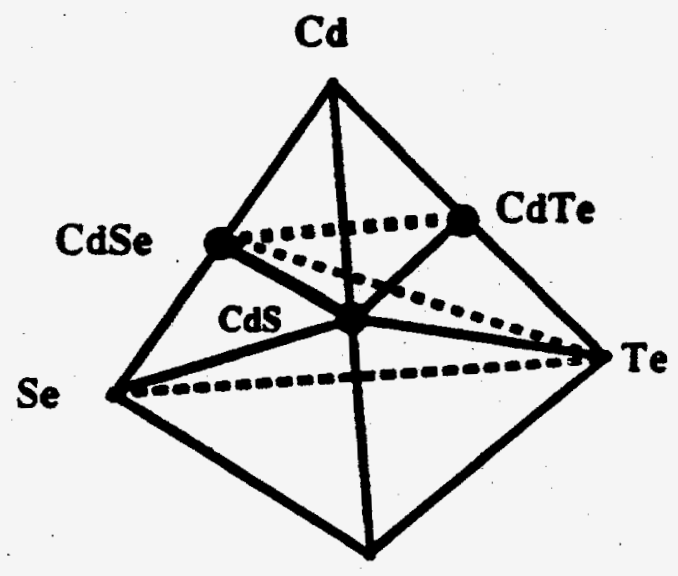

$\mathbf{S}$

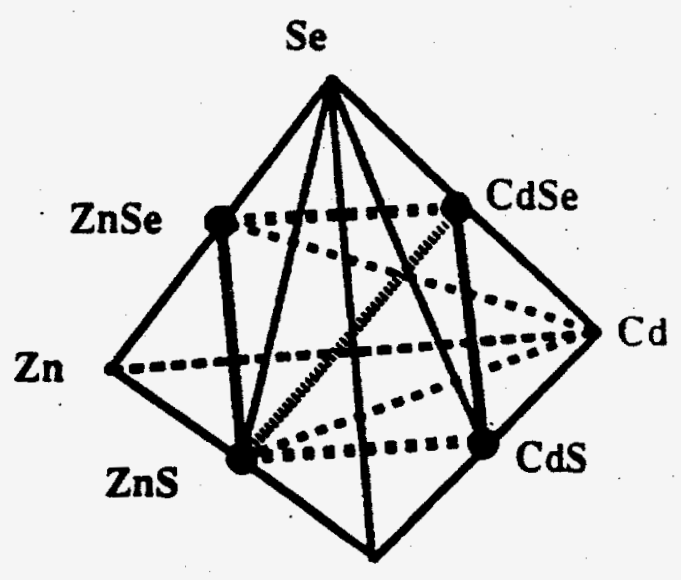

$\mathbf{S}$

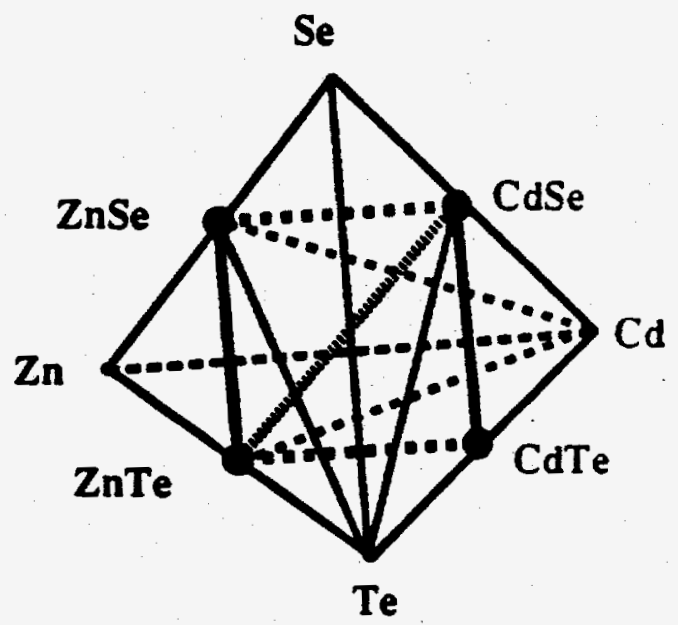

Figure 12. Non-oxygen containing room temperature quateriary phase diagrams for II-VI systems with solid solubility (heavy tie-lines). The left-hand column has ternary solid solutions only, while the right-hand side has both iernary and quatemary solid solutions. Not all tie-lines across the composition ranges are shown. 